\title{
Mineração
}

\section{Métodos de lavra de rochas ornamentais}

\author{
Renato Capucho Reis \\ MSc., Programa de Pós-Graduação em Engenharia Mineral \\ Departamento de Engenharia de Minas \\ Escola de Minas da Universidade Federal de Ouro Preto \\ E-mail:ppgem@em.ufop.br
}

\section{Wilson Trigueiro de Sousa}

Doutor, Professor do Programa de Pós-Graduação em Engenharia Mineral

Departamento de Engenharia de Minas

Escola de Minas da Universidade Federal de Ouro Preto

E-mail:trigueiro@em.ufop.br

\section{Resumo}

Nesse trabalho são apresentados os principais métodos de lavra de rochas ornamentais usados atualmente em muitas pedreiras do Brasil e do exterior. Embora a tecnologia de corte e o beneficiamento sejam aspectos importantes relacionados à produção de rochas ornamentais, o objetivo desse trabalho é apenas descrever os métodos de lavra mais usados. Na ausência de normas técnicas brasileiras que estabeleçam uma classificação apropriada, foi utilizada a classificação mais usada na literatura e na indústria.

Palavras-chave: lavra de rochas ornamentais, métodos de lavra, lavra a céu aberto.

\section{Abstract}

In this study are reviewed the main dimensioned stones mining methods used at the quarries in Brazil and overseas. Although the stone cutting technology and the treatment are important points to be considered in the dimensioned stones production, the main objective of this study is only to describe the main mining methods.

Still nowadays there are not Brazilian technical norms to classify the dimensioned stones mining methods used in the country. Therefore it was used the methods given in the literature and those used by the industry.

Keywords: dimensioned stones mining, quarry mining methods, open pit mining. 


\section{Introdução}

Uma classificação detalhada das rochas ornamentais, considerando a geologia, a orientação e a estética das mesmas, foi feita por Costa (2001). Nesse trabalho, o termo rocha ornamental referese a apenas granitos e mármores, segundo a classificação simplificada largamente utilizada pela indústria. Dessa forma, como granitos são considerados, não apenas os granitos propriamente ditos, mas também gnaisses, migmatitos e sienitos. Como mármores são consideradas as rochas carbonáticas (Destro, 2000).

As jazidas de rochas ornamentais podem ser lavradas em maciços rochosos e em matacões, utilizando-se métodos e técnicas que possibilitam resultados satisfatórios em termos da relação custo/benefício.

Os métodos de lavra consistem num conjunto específico dos trabalhos de planejamento, dimensionamento e execução de tarefas, devendo existir uma harmonia entre essas tarefas e os equipamentos dimensionados. O planejamento inclui a individualização dos blocos com dimensões adequadas à etapa seguinte da cadeia produtiva, representada pelo desdobramento dos blocos em chapas.

É importante verificar, durante a fase do planejamento, se o maciço rochoso ou o matacão possuem características ideais para serem lavrados, como a verificação da existência de impurezas, trincas, alterações, topografia local, etc.

Um planejamento de lavra bem elaborado fornecerá o dimensionamento dos equipamentos e instalações, cálculo de custos, sequiência de atividades, implicações econômicas do impacto ambiental e análise das condições hidrológicas.

Giaconi (1998) concluiu que um bom projeto exige a melhor escolha do método de lavra e a adoção de tecnologias adequadas, nas quais sejam indicados os níveis produtivos desejados, levando-se em conta as características da jazida. Entende-se por melhor escolha o método que proporciona melhor resultado em termos de custo/benefício.
Um outro aspecto importante no planejamento da lavra refere-se à necessidade de serem definidos os possíveis usos futuros da área minerada, uma vez concluída a atividade de lavra.

A preocupação com a qualidade e a quantidade da rocha produzida implica a necessidade de o setor investir em tecnologia para reduzir seus custos. A lavra em maciços rochosos é a que possibilita maiores vantagens operacionais, pois proporciona uma lavra racional com reflexo positivo na relação custo/benefício, havendo uma tendência mundial no sentido de se praticar a lavra de rochas ornamentais em maciços rochosos em detrimento da lavra de matacões. Ambas pode ser praticadas segundo formas diferentes, podendo-se classificar os métodos em lavra do tipo fossa, tipo poço, por bancadas baixas, por bancadas altas, por desabamento e subterrânea.

A lavra em matacões é de concepção mais simples, exigindo, na maioria dos casos, equipamentos pouco sofisticados e mão-de-obra pouco qualificada.

Nos países subdesenvolvidos, onde é difícil a obtenção de crédito para adquirir equipamentos sofisticados e para treinar mão-de-obra especializada, estas jazidas de fácil acesso são lavradas com o uso de técnicas rudimentares. Tais técnicas proporcionam rendimento baixo e produtos de valor agregado igualmente baixo.

\section{Lavra de maciços rochosos}

\subsection{Lavra do tipo fossa}

É um método de lavra que apresenta um impacto visual pequeno, pois a área explotada só pode ser vista de níveis mais elevados. Uma das desvantagens é que atinge facilmente o lençol freático e o bombeamento de água do interior da cava às vezes deve ser constante. $\mathrm{O}$ acesso à frente de lavra é feito através de escadas (do tipo marinheiro) ou de guindastes. Seu uso depende, entre outros fatores, das condições geológicas da jazida.

\subsection{Lavra do tipo poço}

Esse método é mais oneroso que o anterior, pois possui rampas laterais com forte inclinação, que são utilizadas para acesso à frente de lavra. Problemas com inundações e acidentes de trabalho são comuns às pedreiras que utilizam esse método. Nos casos em que a qualidade da rocha oferece condições de estabilidade, o avanço da lavra em profundidade nos tipos fossa e poço pode levar à necessidade de mudança para a lavra subterrânea.

\subsection{Lavra por bancadas baixas}

Consiste em um método com bancadas horizontais baixas, em que uma das dimensões do bloco final não deve ultrapassar 3,0 m, uma vez que o bloco final é retirado da cava com dimensões adequadas ao uso nos teares. Esse método é recomendado para materiais homogêneos, sendo muito flexível para a identificação das partes sãs que serão utilizadas na forma de blocos.

A mecanização é facilitada devido à grande extensão horizontal apresentada. Essa flexibilidade facilita a movimentação de equipamentos (perfuratrizes, carregadeiras) e de blocos. É um método vantajoso em termos de segurança do trabalho, pois evita e reduz de forma considerável o risco de acidentes graves, além de possibilitar um controle minucioso da frente de lavra.

\subsection{Lavra por bancadas altas}

O método de bancadas altas é geralmente usado quando o maciço possui uma altura de 6,0 a 16,0 m. Consiste na abertura de bancadas variando de 3,0 a $6,0 \mathrm{~m}$ de largura e $40,0 \mathrm{~m}$ de comprimento, podendo-se utilizar diferentes tecnologias de corte, em especial o fio diamantado. É caracterizado pela grande incidência de perfuração para fazer a subdivisão em blocos com dimensões adequadas à serragem. É mais oneroso que o método de lavra por bancadas baixas, uma vez que requer uma maior quantidade de mão-de-obra e equipamentos. 


\subsection{Lavra por desabamento}

Chiodi Filho (1998) relata que o desabamento pode ser feito por painéis horizontais ou verticais. $\mathrm{O}$ primeiro caso é recomendado quando o relevo tem inclinação baixa, enquanto que, para se fazer a lavra com painéis verticais, o relevo necessariamente deve ser íngreme.

É um método que exige pouco conhecimento técnico. Algumas das principais vantagens são os baixos custos de operação e o investimento inicial baixo. Geralmente se utiliza um colchão de areia para amortecer a queda da prancha com o objetivo de diminuir o impacto no solo. Esse método apresenta um custo semelhante ao custo da lavra de matacões, mas com o uso de equipamentos de maior porte para limpeza das praças.

\subsection{Lavra subterrânea}

Devido à existência, em todo mundo, de inúmeros depósitos de rochas ornamentais aflorantes ou próximos à superfície, a lavra subterrânea é ainda pouco utilizada. Seu uso é justificado em casos de jazidas de rochas de qualidade excepcional, com alto valor no mercado. Segundo Duarte (1998), a principal mina subterrânea localiza-se nos EUA, no Estado de Vermont. Sua operação foi iniciada em 1870 a céu aberto, passando a subterrânea em 1907. Consiste em uma camada horizontal de mármore com cerca de $500 \mathrm{~m}$ de profundidade, lavrada pelo método de câmaras e pilares, com câmaras e pilares de 15,0 a 20,0 m de largura cada uma.

A lavra subterrânea tem como maior vantagem um impacto ambiental na superfície pequeno. Por outro lado, a lavra subterrânea apresenta grandes dificuldades operacionais, problemas geomecânicos, maior probabilidade de ocorrer acidentes e ainda custo de lavra mais alto que a lavra a céu aberto.

\section{Lavra de matacões}

Os matacões consistem em partes específicas do maciço rochoso, individualizadas a partir da atuação de agentes intempéricos (Destro, 2000, Chiodi
Filho, 1998). Quando os matacões são deslocados por rolamento, adquirem formas arredondas conhecidas por acebolamento.

A lavra de matacões consiste em um método menos oneroso por apresentar custos baixos para abertura de acessos, mão-de-obra pouco qualificada e custos operacionais reduzidos, mas com grandes problemas ambientais.

O esquadrejamento dos blocos é feito através de cunhas manuais ou cunhas pneumáticas, sendo que, no primeiro caso, o processo é mais lento e é recomendado para matacões de até $100,0 \mathrm{~m}^{3}$. No segundo caso, ocorre a utilização de explosivos em furos coplanares e paralelos. As vantagens principais do método são: implantação rápida do empreendimento, investimento inicial baixo, necessidade de pouco conhecimento técnico, equipamentos simples e custo operacional baixo. As desvantagens principais estão relacionadas ao volume grande de estéril produzido, recuperação baixa e dificuldades em um planejamento mais abrangente.

\section{Resultados e conclusões}

A determinação do método de lavra correto em uma pedreira de rochas ornamentais é de importância fundamental para a condução adequada dos trabalhos de planejamento e de execução da lavra. Na fase de definição do método, um erro poderá significar custos de produção excessivamente altos e menor vida útil da pedreira.

A revisão dos métodos de lavra para rochas ornamentais apresentados nesse trabalho pretende ser uma contribuição, de forma sucinta, a um melhor entendimento dos trabalhos necessários à produção de blocos.

A ausência de normas e procedimentos de classificação, tanto da Associação Brasileira de Normas Técnicas ABNT, quanto das associações de produtores, dificulta a sistematização dos métodos de lavra.

\section{Agradecimentos}

Os autores agradecem à CAPES, cujo financiamento viabilizou esse trabalho, e à empresa Minaspérola Ltda, pelas informações fornecidas.

\section{Referências bibliográficas}

CHIODI FILHO, C. Aspectos técnicos e econômicos do setor de rochas ornamentais. Lisboa. Rochas $\boldsymbol{e}$ Equipamentos, n. 51, p. 84-139, 1998.

COSTA, JUSSARA ISMÊNIA. Caracterização mineralógica e tecnológica de uma jazida de serpentinito como rocha ornamental. Ouro Preto: Escola de Minas da Universidade Federal de Ouro Preto. 2001. 101p. (Dissertação de Mestrado em Engenharia Mineral).

DESTRO, ELTON. A influência da esfoliação em maciços graníticos no planejamento da lavra de blocos de rochas ornamentais. Ouro Preto: Escola de Minas da Universidade Federal de Ouro Preto, 2000. 101p. (Dissertação de Mestrado em Engenharia Mineral).

DUARTE, G. W. Método de lavra determina eficácia e rendimento. São Paulo. Rochas de Qualidade, n. 138, p. 91-110, 1998.

GIACONI, W. J. Perfil atual da indústria de rochas ornamentais no município de Cachoeiro do Itapemirim (ES). Campinas: Universidade Estadual de Campinas. 1998. 91 p. (Dissertação de Mestrado em Administração e Política de Recursos Minerais).

REIS, RENATO CAPUCHO. Avaliação de tecnologias de corte em rochas ornamentais. Ouro Preto: Escola de Minas da Universidade Federal de Ouro Preto, 2001. 93p. (Dissertação de mestrado em Engenharia Mineral).

\section{Artigo recebido em 05/05/2003 e aprovado em 11/09/2003.}

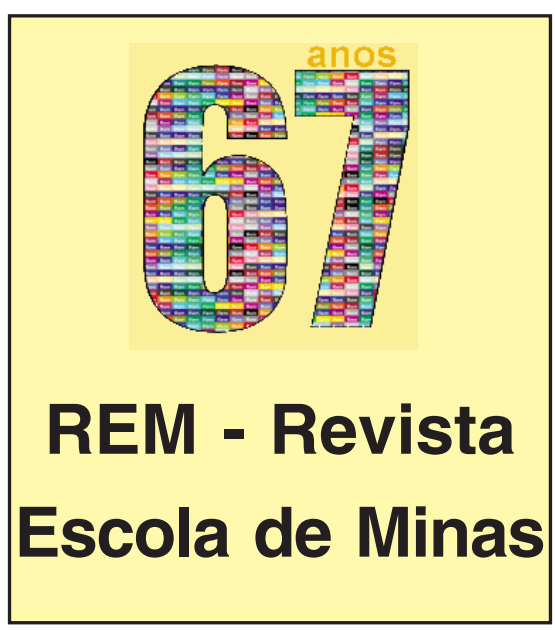

